Çukurova Üniversitesi Mühendislik Mimarlık Fakültesi Dergisi, 35(1), ss. 183-193, Mart 2020

Çukurova University Journal of the Faculty of Engineering and Architecture, 35(1), pp. 183-193, March 2020

\title{
Yumurtalık Fayı'nın Holosen Aktivitesinin Araştırılması (Ceyhan-Adana)
}

\author{
Meryem KARA ${ }^{*}$, Ulvi Can ÜNLÜGENÇ ${ }^{2}$, Hasan ELMACI ${ }^{3}$, Tamer Y. DUMAN ${ }^{4}$ \\ ${ }^{1}$ Maden Tetkik ve Arama Genel Müdürlüğ̈̈, Doğu Akdeniz Bölge Müdürlüğ̈̈, Adana \\ ${ }^{2}$ Çukurova Üniversitesi, Mühendislik Fakültesi, Jeoloji Mühendisliği Bölümü, Adana \\ ${ }^{3}$ Maden Tetkik ve Arama Genel Müdürlü̆g̈̈̈, Jeoloji Etütleri Dairesi Başkanlığı, Ankara \\ ${ }^{4}$ Fugro-Sial Yerbilimleri Müşavirlik ve Mühendislik Ltd. Şti., Ankara
}

Geliş tarihi: 24.12.2019 Kabul tarihi: 15.05.2020

$\ddot{\mathbf{O z}}$

Bu çalışmada, İskenderun Körfezi'ni kuzeyden sınırlayan Yumurtalık Fayı'nın deprem aktivitesi araştırılmıştır. Yumurtalık Fayı'nın deprem üretme potansiyelinin belirlenmesi, etkili olduğu alanlarda tarım, sanayi ve yerleşimin yoğun olması nedeniyle çok önemlidir. Ayrıca Doğu Anadolu Fayı (DAF)'nın Akdeniz'e uzandığı güneybatı kesimini oluşturmasından dolayı DAF'ın depremselliğinin belirlenmesine de önemli katkılar sağlayacaktır. Çalışma kapsamında paleosismolojik hendek kazıları gerçekleştirilmiş ve hendeklerden elde edilen veriler ile fay üzerinde meydana gelmiş ve yüzey yırtılması ile sonuçlanmış en az üç adet deprem tespit edilmiştir. Aletsel dönem deprem kayıtları incelendiğinde, Yumurtalık Fayı ve çevresinde büyüklüğü $M=4$ ve üzerinde birçok depremin meydana geldiği görülmektedir. Fayın uzunluğu ve karakteri gibi fay parametreleri kullanılarak yapılan hesaplamalar sonucunda Yumurtalık Fayı üzerinde meydana gelebilecek en büyük depremin büyüklüğünün 6,9 olması beklenmektedir. Sonuç olarak Yumurtalık Fayı'nın Holosen aktivitesi net olarak ortaya konulmuş ve çalışılan bölgenin neotektonik süreçlerini karşılayan bir mekanizmada çalıştığı görülmüştür.

Bu çalışma, Yumurtalık Fayı'nın geçtiği alanlardaki deprem tehlikesinin değerlendirilmesine yönelik çalışmalara önemli katkılar sağlayacak niteliktedir.

Anahtar Kelimeler: Yumurtalık fayı, Paleosismoloji, Depremsellik, Aktif tektonik

\section{Investigation of Holocene Activity of the Yumurtalık Fault (Ceyhan-Adana)}

\begin{abstract}
In this study, seismic activity of the Yumurtalı Fault, passes through the north of the İskenderun Bay was investigated. The determination of the Yumurtalık Fault's earthquake potential is essential because the region is very important in terms of industry, agriculture and settlement. And also, it has made significant contributions to determine the seismicity of the Eastern Anatolian Fault (EAF) since it forms the southwestern part of the EAF. Paleoseismic trenches were excavated on the Yumurtalik Fault and data obtained from the trenchs revealed at least three earthquakes resulting in surface rupture on the fault. When the seismic records of the earthquake are examined, several earthquakes of $M=4$ and above are reported. Using fault parameters such as length and fault character, it is expected that the greatest
\end{abstract}

*Sorumlu yazar (Corresponding author): Meryem KARA, meryem.kara@mta.gov.tr 
earthquake can occur on the Yumurtalık Fault is 6.9. The Holocene activity of the Yumurtalik Fault is clearly defined and it has been observed that it works in a mechanism meeting the neotectonic processes of the region.

This study will contribute to the evaluation of the earthquake hazard in the areas where the Yumurtalık Fault crosses.

Keywords: Yumurtalık Fault, Paleoseismology, Seismicity, Active tectonic

\section{GİRIŞ}

Ülkemiz tektonik olarak aktif bir bölgede yer almakta olup bu nedenle jeolojik kökenli doğal afetlerin başında gelen deprem, Türkiye'de sıklıkla yaşanmaktadır. Depremlerin mekansal ve zamansal olarak tahmin edilebilirliği deprem kaynaklı can ve mal kayıplarını azaltabilmek açısından son derece önemlidir. Bugünkü teknoloji ile depremlerin oluşum yeri ve zamanı kesin olarak belirlenemese de jeomorfolojik ve paleosismolojik çalışmalar ile bölgede yer alan fayların deprem potansiyelleri araştırılarak sismik tehlike analizleri yapilabilmektedir.
Bir fayın deprem potansiyelinin anlaşılmasında fayın niteliği ve uzunluğu gibi geometrik özelliklerinin yanı sıra fay üzerinde meydana gelmiş depremlerin tekrarlanma aralığı ve fayın kayma hızı da önemli parametrelerdendir. $\mathrm{Bu}$ parametrelerin elde edilebilmessi için fay üzerinde meydana gelmiș olan depremlerin izlerinin tanımlanabilmesi gerekmektedir. Paleosismolojik çalışmalar fayın sismik potansiyelinin çok geniş bir zaman aralığında incelenmesine olanak sağlaması açısından önemlidir.

Bu çalışmada, Yumurtalık Fayı'nın deprem üretme potansiyeli araştırılmıştır. Çalışma alanı, Yumurtalık Fayı'nın geçtiği alan ve yaklaşık 5 km çevresini kapsamaktadır (Şekil 1).

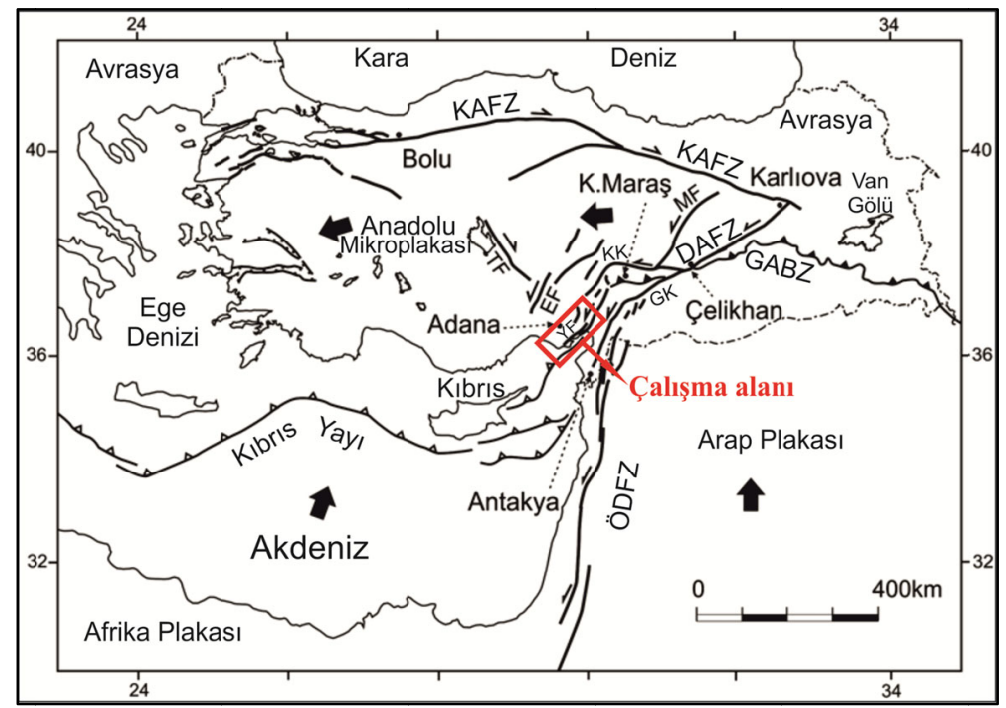

Şekil 1. Çalışma alanının (kırmızı kutucuk çalışma alanını göstermektedir); Anadolu-Arap ve AnadoluAfrika plaka sınırlarında yer alan ana fay sistemleri [3] üzerindeki yeri. Açıklamalar: KAFZ: Kuzey Anadolu Fay Zonu, DAFZ: Doğu Anadolu Fay Zonu, ÖDFZ: Ölü Deniz Fay Zonu, MF: Malatya Fayı, TF: Tuzgölü Fayı EF: Ecemiş Fayı, GABZ: Güneydoğu Anadolu Bindirme Zonu, GK: Doğu Anadolu Fayının Güney Kolu, KK: Doğu Anadolu Fayının Kuzey Kolu ve YF: Yumurtalık Fayı 
Yumurtalık Fayı, tektonik konum olarak, Hatay bölgesinde yer alan Antakya üçlü birleşme noktasının hemen kuzeyinde ve Doğu Anadolu Fayı (DAF)'nın Akdeniz'e uzandığı güneybatı kesiminde yer alması bakımından oldukça önemlidir [1-3]. Yumurtalık Fayı'nın güncel aktivitesinin araştırılması ve deprem üretme potansiyeline ilişkin yorum yapılabilmesi; DAF'ın deprem potansiyelinin anlaşılmasına katkı sağlamasının yanı sıra, etkilediği alanların tarım, sanayi ve nüfus açısından önemli bir bölge olmasından dolayı da ayrıca önem arz etmektedir.

\section{BÖLGESEL JEOLOJI}

Amanos Dağları ve Doğu Torosların batı kesimlerinde yer alan çalışma bölgesi, KD-GB uzanımlı iki ana tektonik hat ile ayrılan 3 havzadan oluşmaktadır. Bu havzaların Miyosen öncesi temel birimleri farklı tektonik kuşaklara aittir [5]. Amanos Dağları batısı ve İskenderun Körfezi'nin kuzeyindeki Yumurtalık Fayı'na kadar olan alanın Neojen dönemindeki çökelim alanı İskenderun Havzası'dır. Mersin-Adana-Karaisalı ve Kozan çevresinden Doğu Torosların güneyine kadar olan alan, Adana Neojen As Havzası ve bu iki havza arasında kalan alan ise Misis-Andırın havzası olarak tanımlanmaktadır [5]. Adana Havzasına, Toros Kuşağı birimleri olan Geyikdağı, Aladağ ve Bozkır birlikleri temel oluşturmaktadır $[5,6]$. İskenderun Neojen Havzasının temel birimleri Arap-Afrika platform istifi, Koçali ofiyolit karmaşı̆̆ı ve Kızıldağ ofiyolitinden oluşmaktadır [5]. Misis-Andırın Havzasına temel teşkil eden birimler ise kenet kuşağında yer alan ofiyolitik melanj ve Toros kuşağına ait alloktonlar olup, bu birimler Pötürge Metamorfitleri, Maden ve Ballıkısık karmaşığı, Dokuztekne volkanitleri, Bodrumkale Formasyonu, Yüksekova karmaşığı, Berit meta-ofiyolitleri, Malatya-Keban metamorfitleri ve Misis- Andırın karmaşığı olarak tanımlanmaktadır [5]. Misis yapısal yükseliminin gelişim süreci çalışma alanındaki tektono stratigrafinin gelişmesinde etkili olmuş olup, bu yapı bölgenin depremselliği ve jeolojik geçmişini anlamak açısından önemli bir tektonik uzanım konumundadır [6]. Stratigrafik kanıtlar, Misis yapısal yükselimini oluşturan çökellerin deformasyonunun Erken-Orta Miyosen'de başladığını ve Pliyosen ve Kuvaterner'de devam ettiğini göstermektedir [8].

Çalışma alanı İskenderun ve Misis-Andırın havzaları arasında yer almaktadır. Misis-Andırın havzası geç Oligosen ve Miyosen yaşlı çökeller üzerine gelen Plio-Kuvaterner yaşlı çökeller ile Adana ve İskenderun havzalarına ait bazaltik lavlardan oluşmaktadır [9]. İki dilimden oluşan Misis-Andırın havzasının KB kanadında Bulgurkaya Olistostromu ve üzerine ilksel ilişkili olarak gelen Alt Miyosen yaşlı Gebenköy Formasyonu yer alırken, GB kanadında yer alan ikinci dilim ise Alt-Orta Miyosen yaşlı Aslantaş ve Karataş formasyonlarının çökelim alanıdır [5]. İnceleme alanında Alt-Orta Miyosen yaşlı Karataş Formasyonu, Üst Miyosen yaşlı Kızıldere Formasyonu, Kuvaterner yaşlı Delihalil Volkanitleri ve alüvyonlar yer almaktadır. En yaşlı birim Alt-Orta Miyosen yaşlı türbiditik özellikli Karataş Formasyonu'dur. Birim çalışma alanında Üst Miyosen yaşlı Kızıldere Formasyonu üzerine tektonik dokanakla gelmektedir. Çalışma alanının doğusunda Kuvaterner yaşlı Delihalil volkanitleri yer almakta olup tüm bu birimler alüvyonlar tarafından açısal uyumsuzluk ile örtülmektedir.

\section{BÖLGESEL TEKTONİK}

Doğu Anadolu Fayı, Anadolu plakası ile Arap plakasını ayıran sol yanal yönlü doğrultu atımlı kıta içi transform fayıdır [10,11]. Doğu Anadolu Fayı ile Kuzey Anadolu Fayı arasinda kalan Anadolu levhasının batıya doğru rotasyonel hareketi sonucunda, Doğu Anadolu sıkışma bölgesi, Kuzey Anadolu Bölgesi, Orta Anadolu ova bölgesi ve Batı Anadolu genişleme bölgesi oluşmuştur [12]. Yumurtalık Fayı tektonik konum olarak Güneydoğu Anadolu'da, Doğu Anadolu sıkışma bölgesinin en güneybatı kesiminde yer almaktadır [12]. Bu bölgede yer alan tektonik yapılar genellikle sol yanal doğrultu atımlı faylardan oluşmaktadır $[8,9,13,14]$. Yumurtalık Fayının aktivitesi, Afrika ve Avrasya plakaları arasında devam eden kuzey-güney yönlü dalmabatma etkisiyle, Anadolu levhasının batıya kaçışı ile ilişkilidir ve doğrultu atımlı bir mekanizmaya sahiptir [4]. Çalışma alanı Tetis'in güney kolunun kapandığ 1 kenet kuşağında yer aldığından dolayı 
Kretase'den bu yana çok aktif bir tektonizma geçirmiştir [5]. Bölgenin Miyosen sonrasında iki farklı tektonik rejim etkisi altında kaldığ düşünülmektedir. Miyo-Pliyosen döneminde etkili olan sıkışmalı doğrultu atımlı rejim yerini Pleyistosen'de açılmalı doğrultu atımlı rejime bırakarak günümüze kadar devam etmiştir [15-17]. Adana ve İskenderun havzasında yapılan çalışmalar bölgede genişlemeli tektonik rejim etkisi altında gelişen yapıların varlığını ortaya koymuştur $[13,18]$.

\section{MATERYAL VE METOT}

\subsection{Materyal}

$\mathrm{Bu}$ çalışmadaki materyal Yumurtalık Fayı ve çevresindeki Kuvaterner yaşlı birimlerden oluşmaktadır. Fayın Kuvaterner aktivitesinin araştırılabilmesi için Kuvaterner yaşlı birimlerde meydana getirdiği deformasyonların belirlenmesi gerekmektedir. Detaylı arazi çalışmaları ve hava fotoğrafları analizi sonucunda fay tarafindan etkilenen Kuvaterner birimleri üzerinde uygun hendek alanı belirlenmiştir. Açılan hendek duvarlarından alınan örneklerin tarihlendirilmesi ile fay üzerinde meydana gelen depremlerin oluşum zamanları tespit edilebilmektedir.

\subsection{Metot}

Büyük ölçekli depremler sonucunda yüzeyde gelişen deformasyonlar bu depremleri üreten fayların özelliklerine bağlıdır. $\mathrm{Bu}$ izlerin oluşturduğu morfoloji kullanılarak Yumurtalık Fayı'nın uzanımı hakkında bilgi toplanmıştır. Fayın, özellikle Kuvaterner birimleri ve daha güncel (Holosen) çökeller üzerinde meydana getirmiş olduğu deformasyon izleri hava fotoğrafları yardımı ile belirlenerek olası hendek yerleri saptanmış ve paleosismolojik hendek kazıları gerçekleştirilmiştir.

Paleosismolojik hendek çalışmaları; depremlerin meydana getirmiş olduğu deformasyon yapılarının hendek duvarlarında belirlenmesi, depremden etkilenen ve depremden önce çökelen en genç birim ile depremden etkilenmeyen ve depremden hemen sonra çökelen ilk birimlerin tarihlendirilmesine dayanmaktadır [19]. $\mathrm{Bu}$ çalışma kapsamında açılan hendeklerden belirlenen seviyelerin tarihlendirilmesi radyokarbon (14C) ve Optik Uyarılmış Işıma (OSL-optically stimulated luminescence) yaş tayin yöntemleri ile gerçekleştirilmiştir.

\section{ARAŞTIRMA BULGULARI}

\subsection{Tarihsel Dönem Depremleri}

Eski adı Ayas olan Yumurtalık"ın kuruluşu M.Ö. 4. yy'a uzanmaktadır. Bir liman şehri olarak bilinen ilçe ve çevresinde yerleşim çok eskiye dayanmaktadır. $\mathrm{Bu}$ bölgede meydana gelen depremler genellikle o zamanın önemli yerleşim ve ticaret kenti olan İskenderun, Anavarza ve Misis yörelerindeki kayıplar dikkate alınarak kayıtlara geçmiştir (Şekil 2).

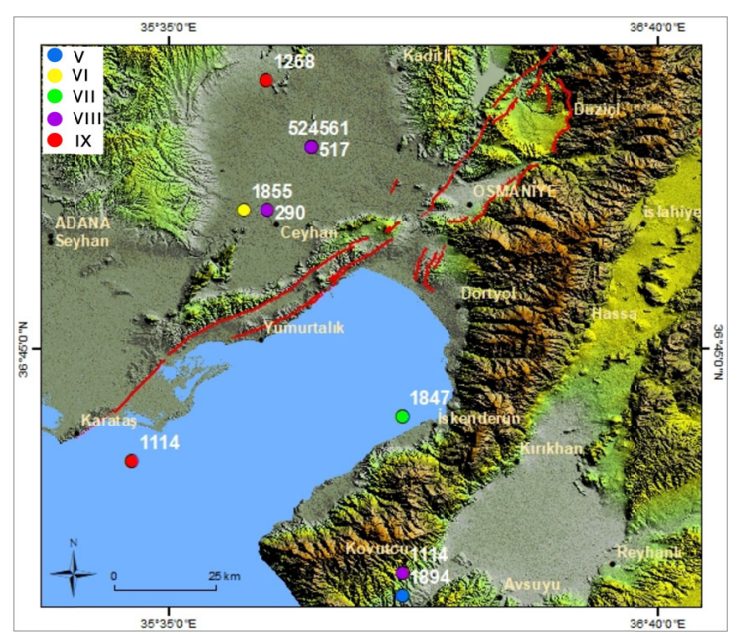

Şekil 2. İnceleme alanı ve yakın çevresinde gerçekleşmiş tarihsel dönem depremlerinin yaklaşık lokasyonları (lokasyonlar [20]'den, diri faylar [14]'den alınmıştır)

\subsection{Aletsel Dönem Depremleri}

Türkiye'de aletsel dönem 1900'den günümüze kadar olan dönemi kapsamaktadır. Aletsel deprem katalogları incelendiğinde, son yüzyılda, çalışma alanında yüzey kırığı oluşturan bir depremin olmadığ1 fakat büyüklüğü 4 ve 4 'den büyük çok sayıda depremin meydana geldiği görülmüştür 
(Şekil 3). Bunlardan en önemlisi Mw: 6.2 büyüklüğündeki 27.06.1998 tarihli Ceyhan-Adana depremidir.

\subsection{Paleosismolojik Hendek Kazıları}

Paleosismoloji tarih öncesinde meydana gelmiş depremlerin yeri, zamanı ve büyüklüğünü araştıran bir bilim dalıdır [25]. Deprem esnasında yüzeyde meydana gelen deformasyonların belirlenmesi amaciyla kullanılan en yaygın yöntem fay boyunca hendek açma yöntemidir. $\mathrm{Bu}$ çalışmada da Yumurtalı Fayı üzerinde iki alanda paleosismolojik hendek kazısı gerçekleştirilmiştir.

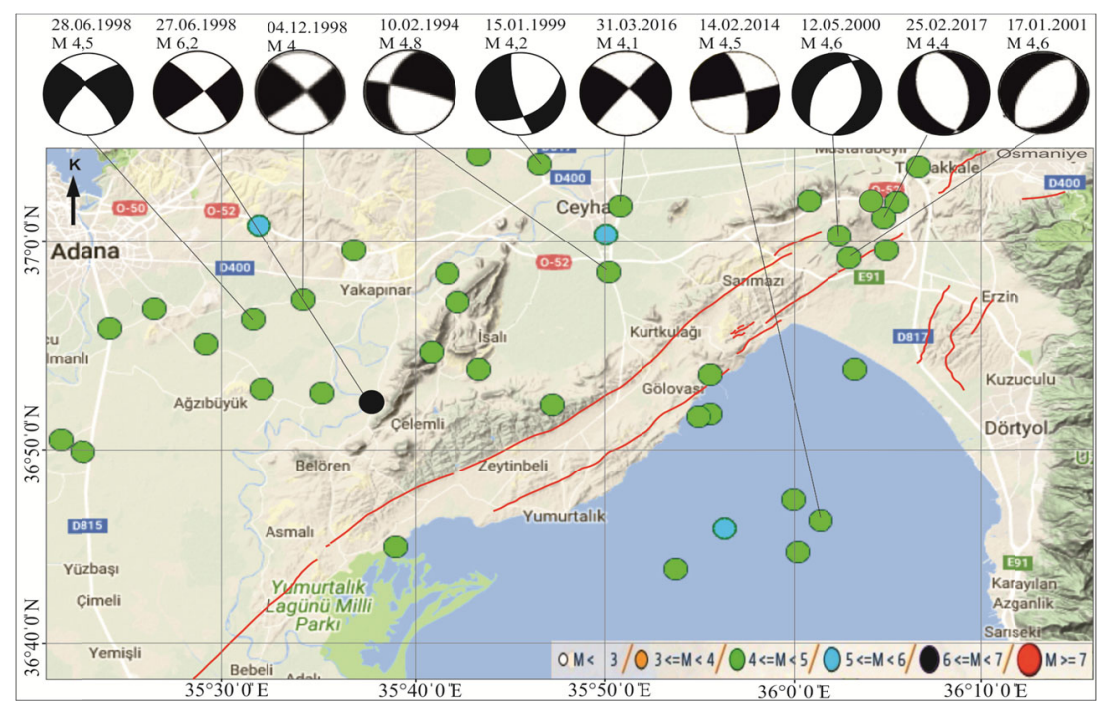

Şekil 3. İnceleme alanı ve yakın çevresinde aletsel dönemde meydana gelmiş dlepremlerin dağılım haritası ve odak mekanizma çözümleri (lokasyonlar [21]'den alınarak revize edilmiştir, diri faylar [14]'den, düzlem çözümleri [4, 22-24]'den alınmıştır)

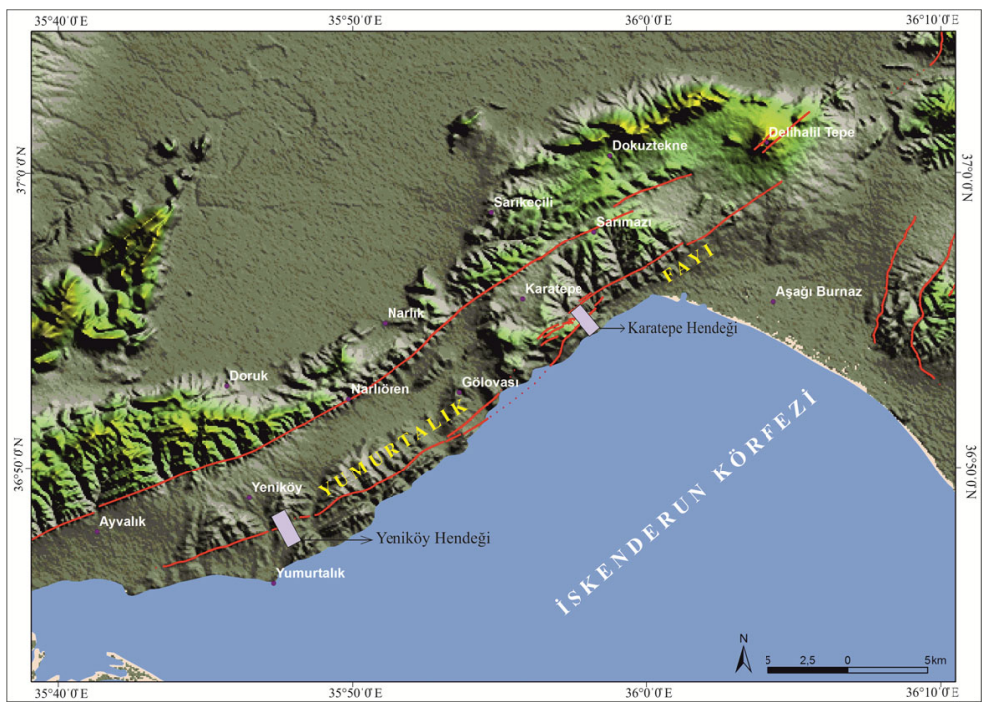

Şekil 4. Yumurtalık Fayı üzerinde açılan hendeklerin lokasyonları (mor kutular hendek lokasyonlarını göstermektedir, diri faylar [14]'den alınmıştır) 


\subsubsection{Yeniköy Hendeği}

Yeniköy hendeği Yumurtalık Fayı'nın Karataş formasyonu ile Kizıldere formasyonu arasinda dokanak oluşturduğu batı parçası üzerinde açılmıştır. Hendek lokasyonu Demirtaş Köyü'nün güney batısında, Yeniköy Mahallesi'nin yaklașı $2 \mathrm{~km}$ güneyinde (GPS: 36S 4076285K/ 749175D) yer almaktadır (Şekil 4). Hendek alanı olarak; kuzeyi yükselmiş olan faylı dokanakta, küçük yelpazelerin ve kolüvyal birikintilerin olabileceği bir alan seçilmiş̧ir. Faya dik bir doğrultuda, yaklaşı $15 \mathrm{~m}$ uzunluğunda açılarak 10 metresi loglanan hendeğin genişliği 3,5- 4 metre, derinliği ise 2,5-3 $\mathrm{m}$ arasında değişmektedir.

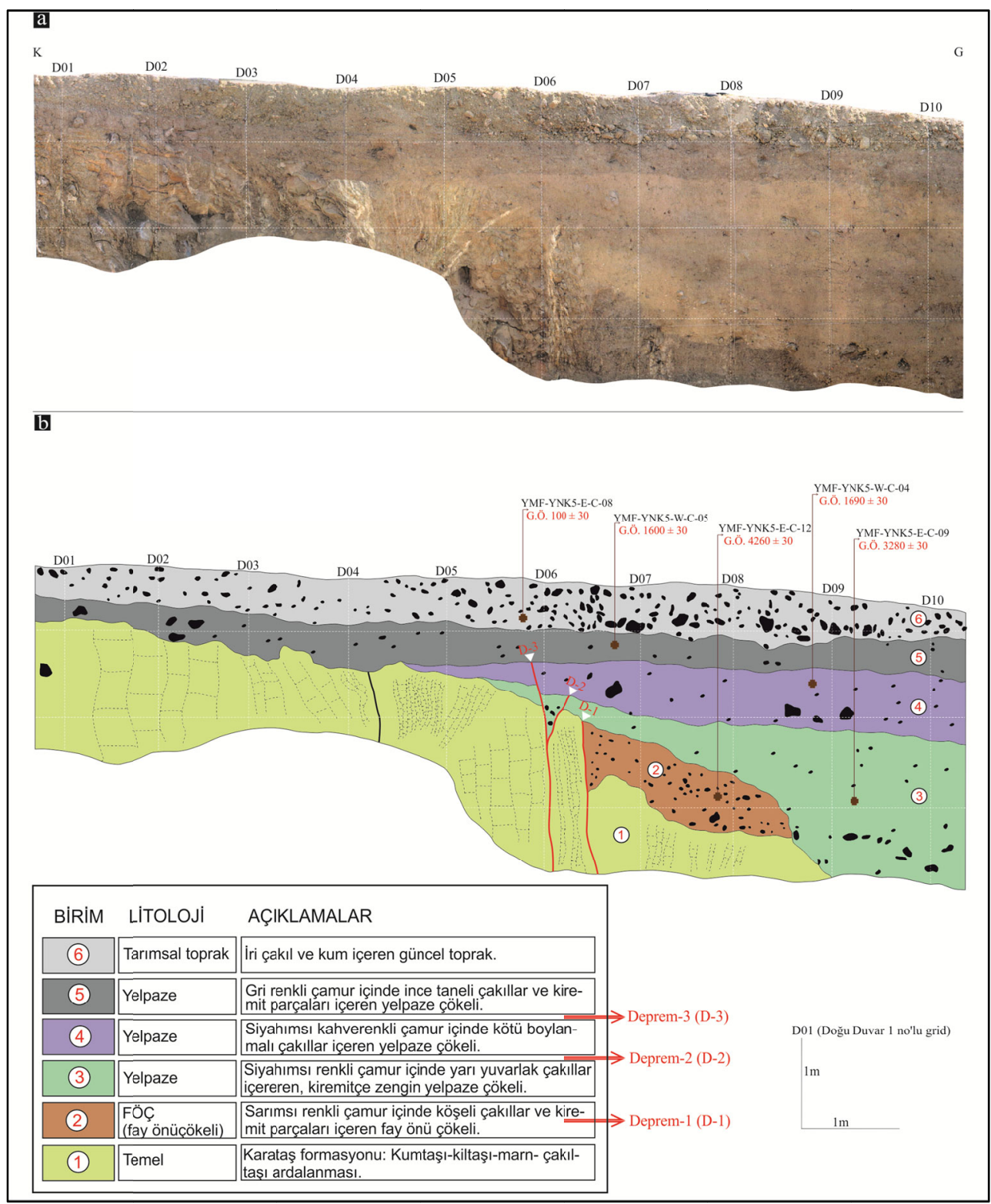

Şekil 5. Yeniköy Hendeği doğu duvarı: a) yorumsuz fotomozaik görüntüsü, b) yorumlanmış hendek logu 
Hendek duvarında, en altta Miyosen yaşlı temel birim ve üzerinde gelişen Kuvaterner yelpaze çökelleri olmak üzere toplamda 6 adet çökel paketi ayırtlanmıştır (Şekil 5a,b). Hendek boyunca gözlenen temel birim (1 no'lu birim) ilksel konumunu kaybetmekle beraber tabakalı bir yapı sergilemektedir. Tabanda gözlenen bej renkli, kumtaşı, silttaşı ve kiltaşı ardalanmasından oluşan türbidit özellikli Karataş Formasyonu (1 no'lu birim) üzerinde, fay zonu önünde, bir deprem esnasında gelişmiş fay önü çökeli (2 no'lu birim) oluşmuştur (Şekil 5). Deprem esnasında güneye eğimlenen alanda temel birimden düşen kötü boylanmalı ve köşeli çakıllar içeren 2 no'lu birimden alınan organik sediman örneği ile birimin yaşı GÖ 4260 \pm 30 yıl (GÖ: günümüz öncesi), kalibre edilmiş çökelim zamanı ise MÖ 2910-2875 olarak belirlenmiştir. 1 ve 2 no'lu birimleri üzerleyen 3 no'lu birim ise siyahımsı renkli çamur içinde çakıllar içeren, kiremitçe zengin yelpaze çökelidir. 3 no'lu birimden alınan kömürleşmiş malzeme örneğinden yapılan radyokarbon yaş tayini ile birimin yaşı GÖ $3280 \pm 30$ y1l, kalibre edilmiş çökelim zamanı ise MÖ 1625-1500 olarak belirlenmiştir. Siyahımsı kahverenkli çamur içinde kötü boylanmalı çakıllar içeren 4 no'lu birim, 3 ve 1 no'lu birimi erozyonal olarak üzerlemektedir (Şekil 5). $\mathrm{Bu}$ birimden alınan kömürleşmiş malzeme örneğinden GÖ $1690 \pm 30$ y1l sonucu alınmış ve bu sonucun kalibrasyonu ile en genç çökelme zaman aralığı MS 255-295 olarak belirlenmiştir. 4 no'lu birimin üzerinde ise gri çamur içinde ince çakıllar ve kiremit parçaları içeren yelpaze çökeli (5 no'lu birim) yer almaktadır (Şekil 5). Bu birimden alınan organik malzeme örneği ile birimin yaşı GÖ $1600 \pm 30$ yıl, kalibre edilmiş en erken çökelme zamanı ise MS 395-540 olarak belirlenmiştir. Hendekte tanımlanan en son seviye ise çakıl ve kum içeren güncel toprak (6 no'lu birim) seviyesidir (Şekil 5). Güncel toprak kalınlığı hendekte $25 \mathrm{~cm}$ ile $55 \mathrm{~cm}$ arasında değişmektedir. $\mathrm{Bu}$ seviyeden alınan organik sediman örneği ile birimin çökelim yaşı GÖ̉ $100 \pm 30$ yıl, kalibre edilmiş en erken çökelme zamanı ise MS 1680-1735 olarak belirlenmiştir.

Yapisal ve stratigrafik unsurlar birlikte değerlendirildiğinde, hendek duvarlarında gözlenen stratigrafik birimleri kesen faylar üzerinde meydana gelen depremlerin bir takım deformasyonlara da neden olduğu gözlenmektedir. Yeniköy hendeğinde her iki duvarda da Holosen döneminde yüzey yırtılmasıyla sonuçlanmış 3 adet deprem meydana geldiği tespit edilmiştir (Şekil 5a,b). İlk deprem 1 no'lu birimi kesmiş ve köşeli çakıllar ve kiremit parçaları içeren 2 no'lu birim (fay önü çökeli) bu deprem esnasında 1 no'lu birim önünde çökelmiştir. 3 no'lu birimin ise bu depremin meydana geliş zamanından sonra çökeldiği düşünülmektedir. Bu depremin 2 no'lu birimin çökelim zamanında meydana geldiği söylenebilir. İkinci deprem 3 no'lu birimi keserek 4 no'lu birim tarafindan üzerlenmektedir. $\mathrm{Bu}$ durumda bu depremin 3 no'lu birimin çökeliminden sonra, 4 no'lu birimin çökeliminden önce gerçekleştiği söylenebilir. Kalibre edilmiş $\mathrm{C}^{14}$ yaşları ile 3 no'lu birimin MÖ 1625-1500 yılları arasında 4 no'lu birimin ise MS 255-295 yılları arasında çökeldiği ve dolayısıyla hendekte tanımlanan 2. depremin MÖ 1625-M.S. 295 yılları arasında meydana geldiği söylenebilir. Hendekte tanımlanan son deprem ise 4 no'lu birimde yüzey yırtılması oluşturarak 5 no'lu birim tarafindan örtülmüştür. 5 no'lu birimin çökelim zamanı da MS 395-540 olarak belirlendiğinden dolayı bu depremin meydana gelmiş olabileceği zaman aralığ da MS 255-540 olarak verilebilir.

Depremlerin tekrarlanma periyoduna ilişkin herhangi bir yorum yapılamamasına karşın hendek duvarında izine rastlanılan son depremin MS 255-540 yılları arasında meydana geldiği varsayılarak bu segment üzerinde yaklaşık 1500 yıldır yüzey yırtılmasıyla sonuçlanmış bir deprem oluşmadığı söylenebilir.

\subsubsection{Karatepe Hendeği}

Karatepe hendeği Karatepe Köyü’nün yaklaşık 2,5 km doğusunda (GPS: 36S 4089383K/763866D), Yumurtalık Fayı'nın doğu parçası üzerinde, fayın doğrultusuna dik olarak açılmıştır (Şekil 4). Hendek yeri seçiminde, depremin izlerinin korunmuş olması ve güncel çökellerin bulunduğu bir alan belirlenmesi önemli olduğundan dolayı, Karatepe hendeği de doğrultu atımlı fayların morfolojide bıraktığı izlerden olan çöküntü 
alanında (sag pond) açılmıştır. Hendek uzunluğu yaklaşık $12 \mathrm{~m}$, genişliği $3,5-4 \mathrm{~m}$ ve derinliği 2,5-3,5 $\mathrm{m}$ arasında değişmektedir. Karatepe hendeğinde güncel toprak da dâhil olmak üzere toplamda 7 adet çökel paketi ayırtlanmıştır (Şekil 6a,b).

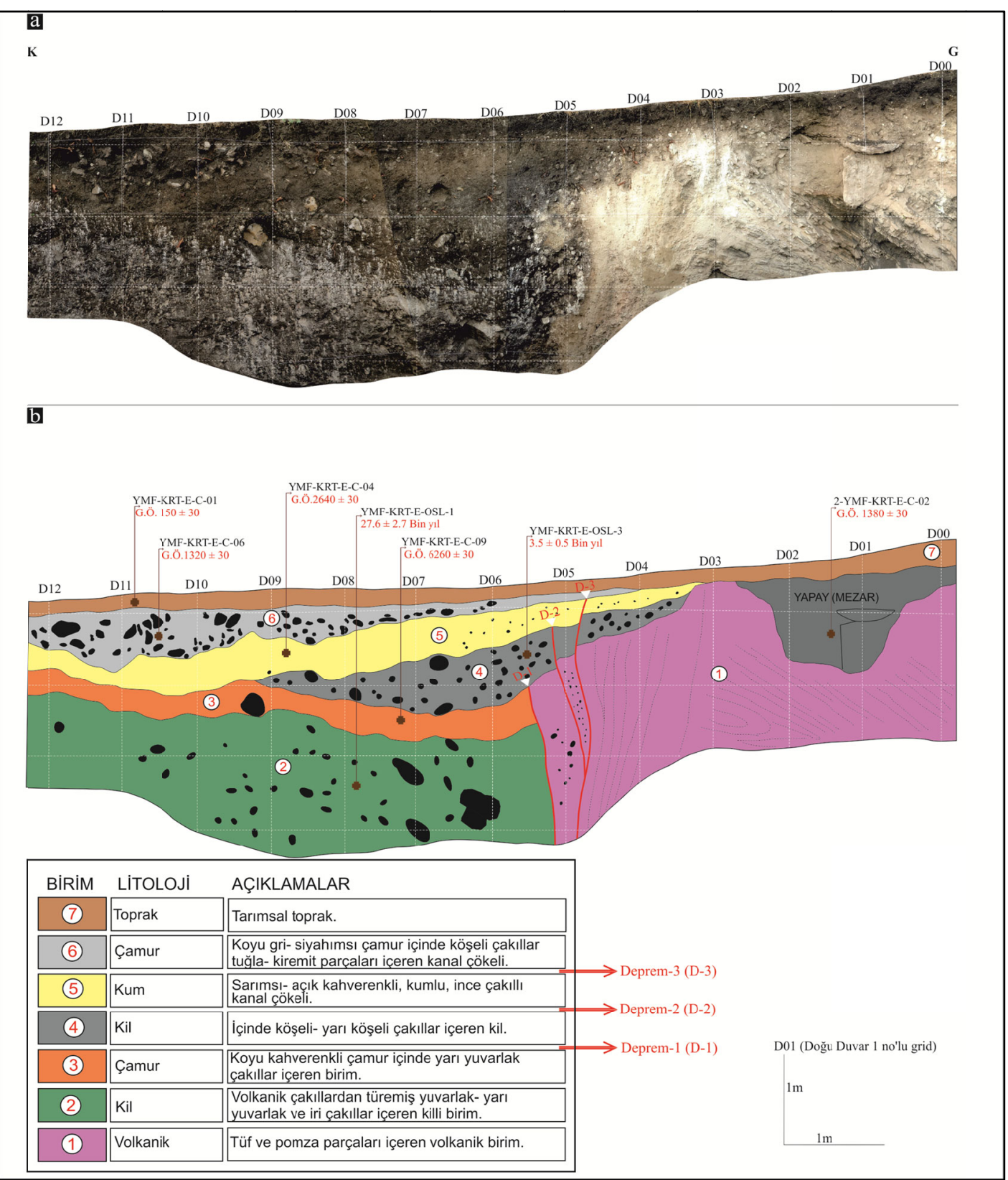

Şekil 6. Karatepe Hendeği doğu duvarı: a) yorumsuz fotomozaik görüntüsü, b) yorumlanmış hendek logu

Hendeğin en tabanında Kuvaterner tüf ve pomza parçaları içeren birim (1) ve bunun volkanizmasının ürünleri olan, bej renkli, tabakalı önünde volkanik, yuvarlak-yarı yuvarlak çakıllar 
içeren killi birim (2) yer almaktadır (Şekil 6). 2 no'lu birimden alınan OSL örneği ile bu birimin yaşı $27,6 \pm 2,7$ bin yıl olarak belirlenmiştir. 2 no’lu birimin üzerinde yarı yuvarlak volkanik çakıllar içeren siyahımsı renkte çamur (3 no'lu birim) bulunmaktadır (Şekil 6). 3 no'lu birimden alınan organik maddece zengin toprak örneğinin radyokarbon yaş tayini GÖ $6216 \pm 30$ sonucunu vermiş ve bu sonucun kalibrasyonu ile birimin en erken MÖ 5210-5310 aralığında çökeldiği belirlenmiştir 2 ve 3 no'lu birim fay tarafindan 1 no'lu birim ile karşı karşıya getirilmiş ve içinde köşeli-yarı köşeli çakıllar bulunan killi birim (4 no'lu birim) ile üzerlenmiştir (Şekil 6). 4 no’lu birimden alınan OSL örneği ile birimin yaşı 3500 \pm 500 y1l olarak belirlenmiştir. 4 no'lu birimin de üzerinde sarımsı, açık kahve renkli ince çakıllı ve kumlu (5 no'lu birim) kanal çökeli bulunmaktadır (Şekil 6). 5 no'lu birimden alınan organik sediman örneğinin radyokarbon yaş tayini sonucuna göre birimin yaşı $2640 \pm 30$, kalibre edilmiş çökelme zamanı ise MÖ 830-790 olarak belirlenmiştir. 5 no'lu birim de içinde tuğla ve kiremit parçaları da bulunan, koyu gri siyahımsı çamur olarak tanımlanan 6 no'lu birim tarafindan üzerlenmektedir. 6 no'lu birimden alınan kömürleşmiş malzeme örneği ile yapılan radyokarbon yaş tayini birimin yaşını $1320 \pm 30$ yıl, kalibre edilmiş çökelme zamanını ise MS 655-720 olarak vermiştir.

Hendeğin en üst seviyesinde ise bütün birimleri üzerleyen, gevşek yapıda, içinde bitki kökleri ve çakılların da bulunduğu tarımsal toprak (7 no'lu birim) yer almaktadır (Şekil 6). En üst seviyeden alınan kömürleşmiş malzeme örneğine göre bu birimin yaşı $150 \pm 30$ yıl olarak belirlenmiştir. Karatepe hendeğinde her iki duvarda da Holosen döneminde yüzey yırtılması ile sonuçlanmış 3 adet deprem izine rastlanmıştır. Bu depremlerden ilki 2 ve 3 no'lu birimi kesip 4 no'lu birim tarafindan örtülmüştür. 3 no'lu birimden alınan numunenin radyometrik yaş analizi sonucunda çökelme zamanı en erken MÖ 5310-5210 olarak belirlenmiştir. 4 no'lu birimden alınan OSL örneğine göre bu birimin yaşı $3500 \pm 500$ yıl olarak belirlenmiştir. Buna göre ilk depremin MÖ 5210-5310'dan sonra meydana geldiği söylenebilir.
Hendek duvarında izine rastlanan ikinci depremin 4 no'lu birimi kesip 5 no'lu birim tarafindan örtüldüğü görülmektedir. Buna göre bu depreminde 5 no'lu birimin çökelim zamanı olan MÖ 830-790'dan önce meydana geldiği söylenebilir. Son deprem ise 5 no'lu birimde yüzey yırtılması meydana getirmiş ve 6 no'lu birim tarafından üzerlenmiştir. $\mathrm{Bu}$ durumda bu depremin, 5 no'lu birimin en erken çökelim zamanı ile 6 no'lu birimin en geç çökelim zamanı olan MÖ 830-MS 720 yılları arasında meydana geldiği söylenebilir.

Hendekte tanımlanan depremlerin tekrarlanma periyoduna ilişkin herhangi bir yorum yapılamamasına karşın hendek duvarında izine rastlanılan son depremin MÖ 830-MS 720 yılları arasında meydana geldiği görülmektedir. $\mathrm{Bu}$ durumda bu segment üzerinde yaklaşık 1300 yıldır yüzey yırtılmasıyla sonuçlanmış herhangi bir deprem oluşmadığı söylenebilir.

\section{SONUÇLAR}

Yumurtalık Fayı, Türkiye'nin güneyinde, İskenderun Körfezinin hemen kuzeyinde, kıyıya paralel bir konumda yer almakta ve Doğu Anadolu Fay Sisteminin bir parçasıdır.

Yumurtalık Fayı boyunca gerçekleştirilen jeolojik ve jeomorfolojik arazi gözlemleri sonucunda, fayın doğrultu atım morfolojisini yansıtacak şekilde çizgisel uzanım ve morfolojik yapılar (ötelenmiş dereler, topoğrafik sırtlar ve çöküntü alanı vb.) sunduğu görülmüştür.

Tüm jeolojik, jeomorfolojik ve paleosismolojik çalışmalar birlikte değerlendirildiğinde Yumurtalık Fayının Holosen aktivitesi net olarak ortaya koyulmuş ve bulunduğu bölgenin Neotektonik süreçlerini karşılayacak şekilde genişlemeli doğrultu atımlı bir mekanizmada çalıştığ sonucuna varılmıştır.

Bu çalışma kapsamında, Yumurtalık Fayı üzerinde açılan her iki hendekte de Holosen döneminde yüzey yırtılmasıyla sonuçlanmış depremlerin izine rastlanmıştır. Açılan hendeklerden elde edilen verilere göre belirlenen depremler arasında 
tekrarlanma periyoduna ilişkin yorum yapılamamaktadır. Ancak son depremden bu yana en az 1500 yil geçtiği söylenebilir.

Aletsel dönem deprem kayıtlarına bakıldığında Yumurtalık Fayı üzerinde büyüklüğü $M=3-4$ arasında birçok depremin meydana geldiği görülmüştür. Tarihsel dönem deprem kayıtları incelendiğinde doğrudan Yumurtalık Fayı ile ilişkilendirilmese de fayın çevresinde birçok depremin meydana geldiği görülmektedir. Hendeklerde izine rastlanan son depremin (MS 255-540) tarihsel dönem kataloglarında yer alan MS 290, MS 517 ve MS 524 depremleri ile ilişkili olabileceği düşünülmektedir.

[3] tarafindan Yumurtalık fayı için 1mm/yıl kayma oranı hesaplanmıştır. Wells ve Coppersmith tarafindan verilen (yüzey kırığı ve oluşturacağı deprem büyüklüğü arasındaki ilişki) bağıntıya göre, doğu ve batı parça olmak üzere iki parçadan oluşan ve toplam uzunluğu $41 \mathrm{~km}$ olan Yumurtalık Fayı'nın tek parça olarak kırılması durumunda $\mathrm{Mw}=6,97$ büyüklüğünde bir deprem üretmesi beklenmektedir.

Son depremden bu yana biriken yamulma gerilimi ve $M w=6,97$ olası deprem büyüklüğü değerleri, Holosen aktivitesi kesin olarak ortaya konmuş olan Yumurtalık Fayı'nın, geçtiği alanlardaki deprem tehlikesinin değerlendirilmesine yönelik çalışmalara önemli katkılar sağlayacak niteliktedir.

\section{TEŞEKKÜR}

$\mathrm{Bu}$ çalışma; Maden Tetkik ve Arama (MTA) Genel Müdürlüğü tarafindan yürütülmüş olan "Doğu Anadolu Fayı (DAF) ve Kuzey Anadolu Fayı (KAF)'nın Doğu Kesimlerinde Paleosismolojik Araştırmalar" projesi kapsamında MTA desteği ile gerçekleştirilmiştir.

\section{KAYNAKLAR}

1. Över, S., Ünlügenç, U. C., 1998. Seismotectonic Evidence of the Antioch Triple Junction and Recent Temporal Change in Quaternary to Present-Day Stress Stage Along
Hatay Region (SE-Turkey), 3. Uluslararas1 Türkiye Jeoloji Sempozyumu Bildiri Özleri Kitab1, 98, Ankara.

2. Yürür, M.T., Chorowicz, J., 1998. Recent Volcanism, Tectonics and Plate Kinematics Near The Junction of the African, Arabian and Anatolian Plates in the Eastern Mediterranean, Journal of Volcanology and Geothermal Research, 85:1-15.

3. Duman, T.Y., Emre, Ö., 2013. The East Anatolian Fault: Geometry, Segmentation and Jog Characteristics, Geological Society, Special Publication, 372:495-529, London.

4. Ergin, M., Aktar, M., Eyidoğan, H., 2004. Present-Day Seismicity and Seismotectonics of the Cilician Basin: Eastern Mediterranean Region of Turkey, Seismological Society of America, 94(3):930-939.

5. Kozlu, H., 1997. Doğu Akdeniz Bölgesi'nde Yeralan Neojen Basenlerinin (İskenderunMisis Andırın) Tektono-Stratigrafi birimleri ve Bunların Tektonik Gelişimi, Çukurova Üniversitesi Fen Bilimleri Enstitüsü-Doktora Tezi, 189, Adana.

6. Özgül, N., 1976. Torosların Bazı Temel Jeolojik Özellikleri, T.J.K. Bülteni, Ankara, 19(1), 65-78.

7. Ünlügenç, U.C., Akınc1, A.C., 2017. Kizıldere-Güveloğlu (Ceyhan-Adana) Civarının Tektono-Stratigrafisi, Çukurova Ünv. Müh. Mim. Fak. Dergisi, 32(2), 85-99.

8. Gökçen, S.L., Kelling, G., Gökçen, N., Floyd, P.A., 1988. Sedimentology of a Late Cenozoic Collisional Sequence: the Misis Complex, Adana, Southern Turkey, Sedimentary Geology, 59, 205.

9. Kelling, G., Gökçen, S.L., Floyd, P.A., Gökçen, N., 1987. Nogene Tectonics and Plate Convergence in the Eastern Mediterranean: New Data from Southern Turkey, Geology, 15, 425-429.

10. Arpat, E., Şaroğlu, F., 1972. Doğu Anadolu Fayı ile İlgili Bazı Gözlem ve Düşünceler, MTA Bülteni, 73, 1-9.

11. Şaroğlu, F., Emre, Ö., Kuşçu, İ., 1992b. The East Anatolian Fault Zone of Turkey, Annales Tectonicae, 6, 99-125.

12. Şengör, A.M.C., Görür, N., Şaroğlu, F., 1985. Strike-Slip Faulting and Related Basin 
Formation in Zones of Tectonic Escape: Turkey as a Case Study (K.T. Biddle\&N. Christie ed.), In: Strike-Slip Deformation, Basin Formation, and Sedimentation, Blick. Soc. Econ. Paleont. and Min., Spec. Publ., 37, 227-264.

13. Williams, G.D., Ünlügenç, U.C., Kelling, G., Demirkol, C., 1995. Tectonic Controls on Stratigraphic Evolution of the Adana Basin, Turkey, Journal of the Geological Society, London, 152, 873-882.

14. Emre, Ö., Duman, T.Y., Özalp, S., Elmacı, H., Olgun, Ş., Şaroğlu, F., 2013. Açıklamalı Türkiye Diri Fay Haritası, MTA Genel Müdürlüğü, Özel Yayın Serisi-30, Ankara.

15. Özden, S., Över, S., Ünlügenç, U.C., 2001. Recent Change i Stress Regime Arunda Niksar Basin, Eastern Part of the Central North Anatolian Fault Zone, Turkey, 4. Uluslararası Türkiye Jeoloji Sempozyumu Bildiri Özleri Kitab1, 194, Adana.

16. Över, S., Özden, S., Ünlügenç, U.C., 2004. Late Cenozoic Stress Distribution along the Misis Range in the Anatolian, Arabian, and African Plate Intersection Region, SE Turkey, Tectonics, 23(TC3008):1-19.

17. Duman, T.Y, Robertson, A.F.H., Elmac1, H., Kara, M., 2017. Palaeozoic-Recent Geological Development and Uplift of the Amanos Mountains (S Turkey) in the Critically Located Northwestern Most Corner of the Arabian Continent, Geodinamica Acta, 29(1), 103-138.

18. Aksu, A.E., Calon, T.J., Piper, D.J.W., Turgut, S., İzdar, E., 1992a. Architecture of Late Orogenic Quaternary Basins in Northeastern Mediterranean Sea, Tectonophysics, 210, 191-213.

19. Allen, C.R., 1986. Seismological and Paleoseismological Techniques of Research in Active Tectonics. (R.E. Wallace Chairman Ed.). in Active Tectonics: Studies in Geophysics, National Academy Press, 148-154, Washington DC.

20. Soysal, H., Sipahioğlu, S., Kolçak, D., Altınok, Y., 1981. Türkiye ve Çevresinin Tarihsel Deprem Kataloğu (MÖ 2100-MS 1900), TÜBITAK, Proje no: TBAG341, yayın no: 563, TBAG seri no: 34, Ankara.
21. AFAD, T.C. Başbakanlık Afet ve Acil Durum Yönetimi Başkanlığı Deprem Dairesi Başkanlığ1, İnternet Sitesi, https://deprem.afad.gov.tr/depremkatalogu.

22. Tan, O., Tapırdamaz, M. C., Yörük, A., 2008. The Earthquake Catalogues for Turkey, Turkish Journal of Earth Sciences, 17, 405-418.

23. Yönlü, 2012. Doğu Anadolu Fay Zonu'nun Gölbaşı (Adıyaman) ile Karataş (Adana) Arasındaki Kesiminin Geç Kuvaterner Aktivitesi, Eskişehir Osmangazi Üniversitesi Fen Bilimleri Enstitüsü, Doktora Tezi, 439.

24. EMSC, The European-Mediterranean Seismological Centre Internet Sitesi, https://www.emsccsem.org/Earthquake/seismologist.php.

25. McCalpin, J., $1996 . \quad$ Paleoseismology Academic Press, San Diego, 613.

26. Wells, D., Coppersmith, K., 1994. New Emprical Relationships Among Magnitude, Rupture Length, Rupture Width, Rupture Area and Surface Displacement. Bull. Seism. Soc. of America, 84(4), 974-1002. 
